\title{
New therapies
}

\section{Summary}

In subjects with type 2 diabetes, both defects of insulin secretion and insulin resistance contribute to the development of hyperglycaemia. The major goals of treatment are to optimise blood glucose control, and normalise the associated lipid disturbances and elevated blood pressure. Pharmacologic treatment is often necessary. This paper discusses new forms of oral treatment for subjects with type 2 diabetes. These include a new sulphonylurea compound glimepiride $\left(\right.$ Amaryl $\left.^{\mathrm{R}}\right)$, which binds to a different protein of the putative sulphonylurea receptor than glibenclamide, and seems to have a lower risk of hypoglycaemia. A new class of drugs with insulin secretory capacity, of which repaglinide (NovoNorm ${ }^{R}$ ) is the leading compound, is now in phase III clinical trials. Alpha-glucosidase inhibitors reversibly inhibit alpha-glucosidase enzymes in the small intestine, which delays cleavage of oligo- and disaccharides to monosaccharides. This leads to a delayed and reduced blood glucose rise after a meal. Two compounds are in development or have been marketed, ie, miglitol and acarbose (Glucobay ${ }^{R}$ ). Another new class of drugs is the thiazolidinediones, which seem to work by enhancing insulin action. The 'insulin sensitising' effects of the leading compounds, troglitazone and BRL 49653C, do not involve any effect on insulin secretion. These drugs also seem to beneficially influence serum cholesterol and triglyceride levels.

Oral antihyperglycaemic agents can be used only during a limited period of time in most patients, after which the diabetic state 'worsens' and insulin therapy has to be started. In this light, two new forms of treatment which require subcutaneous injections are also discussed: the synthetic human amylin analogue AC137 (pramlintide) and glucagon-like peptide-1 (7-36)amide, a strong glucose-dependent stimulator of insulin secretion. It remains to be seen whether these compounds can be developed further for clinical use in patients with diabetes.

Keywords: diabetes mellitus type 2, oral antihyperglycaemic agents, new therapies

\author{
Department of Endocrinology and \\ Metabolism, University Hospital \\ Maastricht, University of Limburg, PO \\ Box 5800, 6202 AZ Maastricht, The \\ Netherlands \\ BHR Wolffenbuttel \\ MB Graal
}

The number of patients suffering from diabetes mellitus is gradually increasing (box 1). Several factors are involved in the development of micro- and macrovascular complications. Hyperglycaemia and its consequences (eg, the formation of advanced glycation end-products and the intracellular accumulation of sorbitol), hypertension, dyslipidaemia and coagulation disturbances play an important role in the pathogenesis of these complications, which seriously affect the life expectancy and quality of life of diabetic patients.

The major goals in the treatment of patients with type 2 diabetes mellitus are to optimise blood glucose control, and to normalise lipid disturbances and blood pressure, in order to relieve complaints due to the hyperglycaemia, improve the well-being of the patient and reduce the risk of development of complications. ${ }^{1}$ Exercise and diet, often aiming at weight normalisation, are considered the cornerstones of therapy. However, pharmacologic treatment is often necessary. Box 2 summarises the classes of oral drugs that are presently used to treat patients with type 2 diabetes.

When one considers the clear relation between elevated blood glucose levels and the presence or risk of development of diabetic complications, it may be expected that medical interventions which improve metabolic control, will reduce the incidence and severity of diabetic complications. It is disappointing to note that direct scientific support for this expectation-at least in the treatment of type 2 diabetes - is lacking. The picture is clearer in case of type 1 diabetes. Here, the relationship between poor metabolic control and the risk of diabetic complications has been demonstrated in numerous studies, while several small-scale studies have indicated that tight control may prevent the development or slow the progression of diabetic complications. ${ }^{2-4}$

The Diabetes Control and Complications Trial (DCCT) is the first largescale study that unequivocally established a reduction in risk of developing diabetic microvascular complications by the achievement of (near) normoglycaemia in type 1 diabetic patients. ${ }^{5}$ It is of importance to note that there seemed to be no threshold level: the lower the HbAlc level, the lower the risk of developing complications.

Although the DCCT investigators did not study patients with type 2 diabetes, it is generally believed that the benefits of improved metabolic control are also relevant for this patient population. This is based on the assumption that the pathogenetic mechanisms which are responsible for the development of microvascular complications are identical in both insulin-dependent diabetes mellitus (IDDM) and non-IDDM (NIDDM) patients, and argue for a similar treatment approach. ${ }^{6}$ This does not necessarily hold true for the development of macrovascular complications; factors like hypertension and dyslipidaemia may be even more important here.

Only a few long-term studies have addressed the effects of therapeutic interventions in type 2 diabetic patients. The preliminary results of the Veterans Administration Cooperative Study showed no benefit of intensive insulin

The diabetes 'epidemic': the number of patients (in millions)

$\begin{array}{llll} & 1994 & 2000 & 2010 \\ \text { Type 1 diabetes } & 11.5 & 18.1 & 23.7 \\ \text { Type 2 diabetes } & 98.9 & 157.3 & 215.6 \\ \text { Total } & 110.4 & 175.4 & 239.3\end{array}$

Source: McCarty D, Zimmet P. Diabetes 1994 to 2010: global estimates and projections. Melbourne. International Diabetes Institute, 1994. 


Oral blood-glucose-lowering
agents used to treat type 2
diabetes
Sulphonylureas (stimulation of insulin
secretion through binding to specific
membrane receptors on $\beta$-cells)
- tolbutamide
- tolazamide
- chlorpropamide
- glibenclamide
- glipizide
- gliclazide
Biguanides (reduction in hepatic
glucose production possibly: increase
in peripheral insulin sensitivity)
- metformin
$\alpha$-Glucosidase inhibitors (inhibition of $\alpha$ -
glucosidase enzymes in the brush
border of the small intestine)
- acarbose

Box 2

\begin{tabular}{|l|}
\hline New oral agents for treat- \\
ment of type 2 diabetes \\
\hline Stimulators of insulin secretion \\
- third generation sulphonylurea: \\
glimepiride (Amaryl ${ }^{\mathrm{R}}$ ) \\
- non-sulphonylurea insulin \\
secretagogues: repaglinide \\
(NovoNorm ${ }^{\mathrm{R}}$ ), meglitinide, KAD \\
1229, A 4166 \\
Insulin 'sensitisers' \\
thiazolidinedione compounds: \\
ciglitazone, pioglitazone, \\
englitazone, troglitazone, BRL \\
49653 \\
Inhibitors of carbohydrate resorption \\
o-glucosidase inhibitors: acarbose, \\
miglitol
\end{tabular}

Box 3 therapy on cardiovascular events. ${ }^{7}$ The UK Prospective Diabetes Study (UKPDS) is expected to report in 1998. More than 5000 patients have been enrolled in the study, in which the effects of treatment with sulphonylurea, metformin, and insulin are compared, to assess whether better metabolic control and more favourable outcome can be achieved with one of these treatments. ${ }^{8,9}$ Since the reported difference in metabolic control between the treatment groups is small (average $\mathrm{HbAlc}$ of the diet group $7.2 \%$ vs $6.5 \%$ in the treatment groups), ${ }^{10}$ it is uncertain whether the UKPDS will give a definitive answer to the questions raised.

In the meantime, new efforts are being made to improve or expand the therapeutic armamentarium to control glycaemia in diabetic subjects (box 3 ). We will review some new treatments for patients with type 2 diabetes.

\section{Sulphonylurea compounds}

Sulphonylurea derivatives stimulate insulin secretion without an effect on insulin synthesis. ${ }^{11}$ Sulphonylureas act by closure of ATP-dependent potassium channels in pancreatic $B$-cells. ${ }^{12}$ This leads to depolarisation of the plasma membrane with opening of voltage-dependent calcium channels with inflow of calcium ions. Calcium ions bind to calmodulin, leading to activation of insulin exocytosis in a similar manner to that found after stimulation with glucose. ${ }^{13}$ Several sulphonylureas are available at present. In general, there are no large differences in effectiveness between the various sulphonylureas. ${ }^{10}$

\section{GLIMEPIRIDE}

Glimepiride $\left(A m a r y l{ }^{R}\right.$ ) is a new, third generation, sulphonylurea, which binds to a different protein of the putative sulphonylurea receptor than glibenclamide. ${ }^{14}$ It has the same insulin secretory effect on pancreatic B-cells as other sulphonylureas but, in contrast to several other sulphonylureas, once daily administration has a similar effect to a twice-daily regimen (Hoechst AG, data on file). Suggested doses are between 1 and $6 \mathrm{mg}$, once daily. Occasionally, doses up to $8 \mathrm{mg}$ may give an additional blood glucose lowering effect. ${ }^{15}$

The hydroxy-metabolite of glimepiride has very minor effects on serum glucose. In contrast, metabolites of glibenclamide possess strong and prolonged effects, contributing to a relatively high incidence of (severe) hypoglycaemia. This was confirmed in a one-year multicentre study, in which glimepiride caused fewer hypoglycaemic reactions than glibenclamide (105 episodes in 60 patients vs 150 episodes in 74 patients), while a similar degree of metabolic control was achieved (mean HbAlc 8.1\%, and mean fasting blood glucose 9.0 $\mathrm{mmol} / \mathrm{l}) .{ }^{16}$ During chronic treatment, serum insulin levels were slightly lower on glimepiride than on glibenclamide, but the observed difference is of doubtful clinical significance.

The effects of glimepiride during exercise are of particular interest. Physical exercise by patients on glimepiride caused the same reduction (by $1.5-1.7$ $\mathrm{mmol} / \mathrm{l}$ ) of serum blood glucose as in subjects treated with glibenclamide. ${ }^{15}$ However, in glimepiride-treated subjects, serum C-peptide levels decreased by $300 \mathrm{pmol} / \mathrm{l}$, while they remained the same in glibenclamide-treated subjects, indicating a beneficial effect of glimepiride in exercise-induced reduction of insulin secretion. This is an additional indication that glimepiride may provoke less hypoglycaemia, for instance on exercise, than glibenclamide.

\section{CARDIOVASCULAR SIDE-EFFECTS}

Recently, other potential side-effects of sulphonylureas have come into focus. In contrast to earlier beliefs, some sulphonylureas, such as glibenclamide, may స్心 interact with human vascular ATP-dependent potassium channels. In a 0 forearm model, it was shown that glibenclamide, at plasma levels found in NIDDM patients treated with the compound, inhibited the normal vasodilation provoked by diazoxide. ${ }^{17}$ This may have consequences for vascular responses $\stackrel{\oplus}{?}$ during ischaemia, which are, at least in part, mediated by ATP-dependent potassium channels.

In experimental animals, it has been suggested that, during ischaemia, shortening of the action potential exerts a protective effect, thereby reducing $\mathbb{\perp}$ contractility, oxygen demand and reperfusion damage. Under these circumstances sulphonylureas such as glibenclamide may inhibit potassium channels $\delta$ in the ischaemic myocardium, and so prevent the shortening of the action potential. This may result in less coronary vasodilatation, more tissue damage, and more reperfusion arrhythmias. The observation that acute administration of $\underset{?}{\rightleftharpoons}$ glimepiride did not interfere with diazoxide-induced vasodilation, while glibenclamide blunted the vasodilatory response has lead to the postulation 
that glimepiride may have less cardiovascular side-effects. ${ }^{18}$ However, it is difficult to extrapolate the results obtained in the somewhat artificial model of the perfused forearm to the clinical situation. In addition, other sulphonylurea than glibenclamide may also have little or no significant effects on vascular ATP-dependent potassium channels, but have not yet been studied.

\section{Non-sulphonylurea insulin secretagogues}

In recent years clinical studies have been carried out on several compounds with similar effects on insulin secretion to sulphonylureas, but with a different chemical structure.

\section{REPAGLINIDE}

Repaglinide (AGEE 623-ZW, NovoNorm ${ }^{\mathrm{R}}$ ) regulates the ATP-sensitive potassium channel via a different binding site to the proposed sulphonylurea receptor. Repaglinide is rapidly and almost completely absorbed from the gastrointestinal tract, which leads to a rapid increase in the plasma concentration. Plasma half-life is less than one hour. It is metabolised in the liver, and none of the known metabolites have any hypoglycaemic effect. The drug is excreted primarily via the bile, and to a small extent $(6 \%)$ via the kidney. This makes it an attractive oral drug for type 2 diabetic patients with diminished kidney function. Its short action is an advantage, incurring a low risk for longstanding hypoglycaemia.

In the first phase II clinical trials it appeared that its effects on metabolic control were similar to the effects of glibenclamide, although at a lower dose (2 $\mathrm{mg}$ twice daily vs $15 \mathrm{mg}$ daily in two divided doses). ${ }^{19}$ Glibenclamide had slightly greater effect on fasting blood glucose. A three-times daily preprandial dosing regimen was more effective than a twice daily regimen in maintaining blood glucose levels at a lower level. Phase III clinical trials are currently underway in 11 countries in Europe and the US.

\section{$\alpha$-Glucosidase inhibitors}

Two compounds of this class of drugs are in development or have been marketed, ie, miglitol and acarbose $\left(\right.$ Glucobay $\left.^{R}\right) . \alpha$-Glucosidase inhibitors reversibly inhibit the $\alpha$-glucosidase enzymes in the brush-border of the small intestine, and delay the cleavage of oligo- and disaccharides to monosaccharides. This delays carbohydrate absorption and thus leads to a delayed and reduced blood glucose rise after a meal. ${ }^{20}$ Acarbose seems to be effective in improving metabolic control in patients with both type $2^{21}$ and type 1 diabetes. ${ }^{22}$ The average decrease of postprandial blood glucose during acarbose treatment in diet-treated type 2 diabetic patients was $3 \mathrm{mmol} / \mathrm{l}$, and the maximal decrease of $\mathrm{HbAlc}$ was $1.0 \% .^{23}$ Comparable results were obtained in sulphonylurea-treated patients. During therapy, plasma insulin levels may decrease by $20-25 \%$; in some studies a decrease of serum triglycerides has been observed. ${ }^{23}$ Acarbose can also be used as an adjunct to insulin in type 1 diabetic patients, and may result in more stable metabolic control, with smoothening of daily blood glucose excursions, and sometimes reduction of insulin requirement. These effects seemed to persist during a 12 -month follow-up period. ${ }^{24}$

\section{MIGLITOL}

Miglitol is derived from 1-deoxynojirimycin, and is structurally similar to glucose. The compound is still in clinical development. It has a similar effect to acarbose on gastrointestinal $\alpha$-glucosidase but is almost completely absorbed from the gut. Previously, we have shown in an acute study in subjects with type 2 diabetes that miglitol reduced postprandial blood glucose excursions, irrespective of the carbohydrate content of the meal, without changes of serum insulin or C-peptide levels. ${ }^{25}$ Any possible long-term advantages of miglitol treatment over acarbose have still to be investigated. Although it is resorbed, no extrapancreatic effects have been demonstrated. ${ }^{26}$

\section{Thiazolidinediones}

The thiazolidinediones are a new class of compounds which seem to work by enhancing insulin action and thus promoting glucose utilisation in peripheral tissues, possibly by stimulating nonoxidative glucose metabolism in muscle, and suppressing gluconeogenesis in the liver. They have no effects on insulin secretion. ${ }^{27}$ Several compounds are now in development, but none have yet reached the phase of registration. ${ }^{28}$ 


\begin{tabular}{|l|}
\hline $\begin{array}{l}\text { Mechanism of action of new } \\
\text { pharmacological compounds }\end{array}$ \\
\hline Thiazolidinediones \\
- stimulation of insulin action \\
- increased peripheral glucose uptake \\
the liver \\
Amylin analogues \\
- slowing of gastric emptying \\
slowing of gastrointestinal glucose \\
absorption \\
Glucagon-like peptide-1 \\
- potentiation of glucose-induced \\
insulin secretion \\
- ? slowing of gastric emptying \\
\hline
\end{tabular}

Box 4
TROGLITAZONE

Troglitazone (CS-045 or GR92132X) was shown to improve insulin resistance and glucose tolerance in obese subjects with either normal or impaired glucose tolerance. ${ }^{29}$ Plasma insulin levels decreased by $48 \%$. In subjects with type 2 diabetes, troglitazone improved insulin resistance, lowered serum insulin levels, and lowered hepatic glucose production, thereby improving both fasting and postprandial blood glucose levels. ${ }^{30}$ It appeared that the decrease of fasting serum glucose is dose-dependent, with an $11 \%$ decrease at a daily dose of $200 \AA$ $\mathrm{mg}$, and a $19 \%$ decrease at an 800 -mg dose during a follow-up of 12 weeks. ${ }^{31}$. Later (European) studies showed a $20 \%$ decrease of serum glucose at a daily $\vec{F}$ dose of $200 \mathrm{mg}$; higher doses had no additional effect (table). ${ }^{32}$ Several studies have reported a concomitant decrease of total cholesterol and triglycerides, and an increase in HDL cholesterol. With respect to serum lipids, there seems to be a dose-dependent response (table).

Data on long-term efficacy are scarce. One abstract reported on one-year follow-up data. A persistent improvement of metabolic control was observed in diet-treated and sulphonylurea-treated type 2 diabetic subjects during the entire period, together with a reduction of serum triglycerides, but not of total cholesterol. Adverse events were oedema (six of 199 subjects), and laboratory abnormalities, including mild anemia and elevation of serum lactate dehydrogenase in 16 subjects. All abnormalities resolved after cessation of the drug. $^{33}$

Interestingly, a decrease of systolic and diastolic blood pressure was observed in some studies of troglitazone. This effect was studied in more detail by Ogihara $e t$ al, who found a decrease of blood pressure from 164/94 to $155 / 82$ $\mathrm{mmHg}$ after eight weeks of treatment with a dose of $200 \mathrm{mg}$ troglitazone bid in 18 subjects with mild type 2 diabetes and hypertension. ${ }^{34}$ Unfortunately, this was an uncontrolled study, and part of the blood pressure reduction may be a study effect. In addition, it has been suggested that troglitazone has antioxidant effects; the compound inhibited oxygen free radical generation in vitro. ${ }^{35}$ Such effects have also been suggested for sulphonylureas like gliclazide. The effects in vivo in humans still have to be assessed.

Animal studies with thiazolidinediones, however, have indicated that some compounds may induce cardiac hypertrophy and dose-dependent decreases in red blood cells and haemoglobin, possibly by selective bone marrow depression. These side-effects have hindered the early development of these compounds. The compounds now in clinical development seem to be devoid of severe sideeffects at the doses used, although the above-mentioned one-year study has reported development of (mild) anaemia. ${ }^{33}$ Careful biochemical evaluation of patients who are treated with thiazolidinedione derivatives may therefore be warranted. It may well be that the low $200 \mathrm{mg}$ dose of troglitazone yields no significant side-effects.

Preliminary results of a one-year study in type 2 diabetic subjects followed with echocardiography, showed no increase in left ventricular mass. A $4.7 \%$ reduction in mean arterial blood pressure and a $12 \%$ increase in stroke volume and cardiac index were observed in troglitazone-treated subjects, while glibenclamide had no effects on these parameters. ${ }^{36}$

\section{Amylin analogues}

Amylin is a 37-amino-acid polypeptide that is synthesised in and secreted from pancreatic $\beta$-cells, together with insulin. Serum concentrations in healthy subjects vary between 5 and $30 \mathrm{pmol} / \mathrm{l}$, but are markedly reduced in type 1

Table Metabolic effects of troglitazone in 330 type 2 diabetic subjects, who were inadequately controlled by diet or diet plus oral antihyperglycaemic agents

\begin{tabular}{|c|c|c|c|c|c|}
\hline & $\begin{array}{l}H b A 1 c \\
(\%)\end{array}$ & $\begin{array}{l}\text { Glucose } \\
\text { (mmol/l) }\end{array}$ & $\begin{array}{l}H D L-C \\
(\mathrm{mmol} / \mathrm{l})\end{array}$ & $\begin{array}{l}\text { Serum } \\
\text { insulin } \\
(m U / l)\end{array}$ & $\begin{array}{l}\text { Triglycerides } \\
\text { (mmol/l) }\end{array}$ \\
\hline placebo & 8.1 & 13.2 & 1.07 & 11.1 & 2.03 \\
\hline $200 \mathrm{mg}$ od & $7.0^{\mathrm{b}}$ & $10.5^{c}$ & 1.11 & 9.8 & 1.80 \\
\hline $400 \mathrm{mg}$ od & 7.5 & $10.7^{\mathrm{c}}$ & 1.06 & $8.9^{\mathrm{b}}$ & 1.78 \\
\hline $600 \mathrm{mg}$ od & $7.2^{\mathrm{a}}$ & $10.2^{c}$ & $1.19^{\mathrm{b}}$ & $8.4^{\mathrm{b}}$ & $1.63^{\mathrm{b}}$ \\
\hline $800 \mathrm{mg}$ od & $7.2^{\mathrm{a}}$ & $10.3^{c}$ & $1.15^{\mathrm{a}}$ & $9.7^{\mathrm{a}}$ & $1.68^{\mathrm{b}}$ \\
\hline $200 \mathrm{mg}$ bd & $7.0^{\mathrm{b}}$ & $10.4^{c}$ & 1.08 & 9.8 & $1.73^{\mathrm{b}}$ \\
\hline $400 \mathrm{mg} \mathrm{bd}$ & $7.3^{\mathrm{a}}$ & $9.6^{\mathrm{c}}$ & $1.15^{\mathrm{a}}$ & $8.2^{c}$ & $1.68^{b}$ \\
\hline
\end{tabular}

${ }^{\mathrm{a}} \mathrm{p}<0.05,{ }^{\mathrm{b}} \mathrm{p}<0.01,{ }^{\mathrm{c}} \mathrm{p}<0.001$ vs placebo. Source: Beck-Nielsen ${ }^{32}$ 
diabetic subjects. Amylin has several metabolic effects in animals, such as stimulation of glycogen breakdown, and lactate formation in skeletal muscle.

The synthetic human amylin analogue AC137 (25,28,29-tripro-amylin, pramlintide) is now in clinical study. Like amylin it is believed that its main action is to slow gastric emptying and therefore slow gastrointestinal absorption of nutrients (box 4). Indeed, it was recently shown that the drug has pronounced effects on gastric emptying. Using radioactively labelled food, Macdonald et al showed that intravenous pramlintide infusion $(25 \mu \mathrm{g} / \mathrm{h}$, resulting in plasma concentrations averaging $130 \mathrm{pmol} / \mathrm{l}$ ) severely increased the median lag time before the liquid food component started to empty from the stomach from 7.5 to $69 \mathrm{~min}$; the lag time for solid food increased from 44.5 to 150 min. ${ }^{37}$ In contrast, an amylin antagonist, AC187, was shown to accelerate gastric emptying in rats.

After either intravenous infusion or subcutaneous injection of pramlintide, reduced postprandial glucose increases were observed following a mixed meal or a Sustacal test meal. Pramlintide had no effect on the glucose course after intravenous administration of glucose. These observations were made in subjects with type $1^{38}$ and type 2 diabetes. ${ }^{39}$ Chronic treatment with pramlintide, administered by subcutaneous injection four times daily, resulted in lower mean 24-hour blood glucose levels in IDDM patients. ${ }^{40} \mathrm{With}$ a dose of three times $30 \mu \mathrm{g}$, plasma concentrations of pramlintide were achieved in the physiological range for human amylin. This dose decreased mean blood glucose by $1.8 \mathrm{mmol} / \mathrm{l}$. The reported side-effects are gastrointestinal, eg, nausea. The long-term effects of pramlintide therapy have to be awaited. Although the concept behind the drug is appealing, the necessity for three daily injections will perhaps hamper wide-spread acceptance by patients. Similar effects on blood glucose may, for example, be achieved by the use of oral $\alpha$-glucosidase inhibitors like acarbose. Also, the degree to which gastric emptying is reduced raises concern.

\section{Glucagon-like peptide-1}

Glucagon-like peptide-1 (GLP-1) is a fragment of the proglucagon molecule. Two shorter forms of GLP-1, the (7-37) and (7-36) amides, are strong glucosedependent stimulators of insulin secretion, as demonstrated both in vitro and in vivo. GLP-1 (7-36)amide is a hormone from the lower intestine. It functions as a so-called incretin hormone, ie, it is released after meals and potentiates insulin secretion during the postprandial phase. ${ }^{41}$ GLP-1 still may promote insulin secretion in subjects with type 2 diabetes, also in those failing on maximal oral antihyperglycaemic therapy. It does not further lower blood glucose at normal blood glucose concentrations. Intravenous infusion of GLP-1 may lower serum glucose concentrations to an almost normal level in overtly hyperglycaemic subjects. It has been suggested that GLP-1 also reduces the postprandial increase of blood glucose levels by delaying gastric emptying (box 4). ${ }^{42}$ After subcutaneous injection, the duration of action is rather short; only when preparations with prolonged action become available may this compound be included in the present-day armamentarium of antihyperglycaemic agents.

\section{Closing remarks}

The most important metabolic effects of the oral compounds that are or shortly will be available for the treatment of patients with type 2 diabetes mellitus are summarised in box 5 . All of these drugs lower blood glucose levels, with a more profound effect in those drugs which also stimulate insulin secretion. Sulphonylureas acutely increase serum insulin levels, which gradually decrease again during chronic treatment. Some authors have suggested a relationship

\begin{tabular}{|lll|}
\hline \multicolumn{3}{|c|}{ Metabolic effects of oral antihyperglycaemic agents } \\
\hline \\
& blood glucose & serum insulin \\
sulphonylureas (SU) & $\downarrow \downarrow$ & $\uparrow$ or $=$ \\
non-SU insulin secretagogues & $\downarrow \downarrow$ & $\uparrow$ or $=$ \\
biguanides & $\downarrow$ to $\downarrow \downarrow$ & $\downarrow$ \\
thiazolidinediones & $\downarrow$ to $\downarrow \downarrow$ & $\downarrow$ to $\downarrow \downarrow$ \\
$\alpha$-glucosidase inhibitors & $\downarrow$ & $\downarrow$ \\
Key: $\downarrow \downarrow$ considerable reduction, $\downarrow$ small reduction, = no change, $\uparrow$ small increase \\
\end{tabular}


between hyperinsulinaemia and the development of cardiovascular disease. ${ }^{43} \mathrm{It}$ is, however, believed that the hyperinsulinaemia associated with type 2 diabetes and the cardiovascular metabolic syndrome is a marker of the insulin-resistant state, not a cause of the vascular sequelae. Therefore, the effect of a drug on serum insulin levels is neither an argument in favour nor against its use in the treatment of diabetes. Nevertheless, efforts to reduce insulin resistance are a crucial component of the management of patients with type 2 diabetes, ${ }^{44}$ as was recently corroborated in an ADA consensus statement.

Despite our knowledge of the mechanism of action of oral antihyperglycaemic agents, it is salutory to note that there are no long-term studies in type 2 diabetic patients which have shown that our medical interventions help to postpone or prevent complications. We need long-term follow-up studies like the UK Prospective Diabetes Study and also to improve post-marketing surveillance studies which follow patients during different treatment modalities. Only then can we assess whether the theoretical advantages of certain antihyperglycaemic agents translate into a more favourable prognosis for our patients.

It has to be kept in mind, however, that oral antihyperglycaemic agents can be used only during a limited period of time in most patients. After a number of years the diabetic state 'worsens', which usually means that residual $\beta$-cell function declines. At that time, insulin therapy will be initiated. Unfortunately, this step usually is taken (too?) late in the course of the disease, due frequently to the reluctance of both the doctor and the patient.

1 Alberti KGMM, Gries FA. Management of noninsulin-dependent diabetes mellitus in Europe: a consensus view. Diabetic Med 1988; 5: 275-81.

2 Hanssen KF, Dahl-Jorgensen $\mathrm{K}$, Lauritzen $\mathrm{T}$, Feldt-Rasmusssen B, Brinckmann-Hansen $O$, Deckert T. Diabetic control and microvascular complications: the near-normoglycaemic experience. Diabetologia 1986; 29: 677-81.

3 Feldt-Rasmussen B, Mathiesen ER, Jensen T, Lauritzen $T$, Deckert $T$. Effect of improved Lauritzen T, Deckert T. Effect of improved type I (insulin-dependent) diabetic patients: an type I (insulin-dependent) diabetic patients: an
update of the Steno studies. Diabetologia 1991; update of the

4 Reichard P, Berglund B, Britz A, Cars I, Nilsson BY, Rosenqvisst U. Intensified conventional insulin treatment retards the microvascula complications of insulin-dependent diabetes mellitus (IDDM): the Stockholm Diabetes Intervention Study (SDIS) after 5 years. $\mathcal{F}$ Interm Med 1991; 230: $101-8$.

5 Diabetes Control and Complications Trial Research Group. The effect of intensive treatment of diabetes on the development and progression of long-term complications in insulin-dependen diabetes. N Engl ₹ Med 1993; 329: 977-86.

diabetes. N Engl f Med 1993; 329: $977-86$.
6 Colwell JA. DCCT findings - applicability and implications for NIDDM. Diabetes Rev 1994; 2 : 277-91.

7 Abraira C, Johnson N, Colwell J, and the VA CSDM Group. VA Cooperative study on gly cemic control and complications in type I diabetes; results of the completed feasibility trial. Diabetes 1994; 43 (suppl1): 59A

8 UK Prospective Diabetes Study. II. Reduction in HbAlc with basal insulin supplement, sulfonylurea, or biguanide therapy in maturity onse diabetes. Diabetes 1985; 34: 793-8.

9 UK Prospective Diabetes Study Group. UK Prospective Diabetes Study (UKPDS). VIII. Study design, progress and performance. Diabetologia 1991; 34: 877-90.

10 Turner RC, Holman RR. Lessons from the UK prospective diabetes study. Diabetes Res Clin Pract 1995; 28 (suppl): S151-7.

11 Gerich JE. Drug therapy - oral hypoglycemic agents. N Engl f Med 1989; 321: $1231-45$

12 Sturgess NC, Ashford MLJ, Cook D, Hales NC. The sulfonylurea receptor may be an ATP sensitive potassium channel. Lancet 1985; ii 474-5.

13 Groop LC. Sulfonylureas in NIDDM. Diabetes Care 1992; 015: 737-54.

14 Kramer W, Muller G, Girbig F, et al. Differential interaction of glimepiride and glibenclamide with the b-cell sulfonylurea receptor II Photoaffinity labeling of a $65 \mathrm{kDa}$ protein by $\left[{ }^{3} \mathrm{H}\right]$ glimepiride. Biochim Biophys Acta 1994 119: 278-90.

15 Goldberg R, Holvey S, the Glimepiride Study Group. A dose response study of glimepiride in patients with NIDDM who have previously patients with NIDDM who have previously (suppl 1): 108A.
16 Draeger E. Clinical profile of glimepiride. Diabetes Res Clin Pract 1995; 28 (suppl 1) S139-46.

17 Bijlstra PJ, Smits P, Lutterman JA, Thien Th Glibenclamide inhibits the vasodilator effect of diazoxide in man. Diabetologia 1994; 37 (supp 1): A162

18 Smits P, Thien T. Cardiovascular effects of sulphonylurea derivatives: implications for the sulp Diabetologia 1995; 38: treatment

19 Wolffenbuttel BHR, Nijst L, Sels JPJE, Menheere PPCA, Muller PG, Nieuwenhuijzen heere PPCA, Muller PG, Nieuwenhuijzen glycaemic agent, repaglinide, on metabolic conglycaemic agent, repaglinide, on metabolic con-
trol in sulphonylurea-treated patients with trol in sulphonylurea-treated patients with 6.

20 Balfour JA, McTavish D. Acarbose - an update of its pharmacology and therapeutic use in diabetes mellitus. Drugs 1993; 46: 1025-54.

21 Toeller M. Efficacy of $\alpha$-glucosidae inhibitors in NIDDM subjects. Eur $\mathcal{f}$ Clin Invest 1994; 24 (suppl 3): 31-5.

22 Rios MS. Acarbose and insulin therapy in type 1 diabetes mellitus. Eur f Clin Invest 1994; 24 (suppl 3): 36-9.

23 Hanefeld $M$, Fischer S, Schulze J, et al Therapeutic potentials of acarbose as first line Trug in non-insulin dependent diabetes insufficiently treated with diet alone. Diabetes Care ciently treated with

24 Josse RG. Acarbose for the treatment of type II diabetes: the results of a Canadian multi-centre trial. Diabetes Res Clin Pract 1995; 28 (suppl): S1677-72.

25 Kingma PJ, Menheere PPCA, Sels JP, Nieuwenhuijzen Kruseman AC. Alpha-glucosidase inhibition by miglitol in NIDDM patients. Diabetes Care 1992; 15: 478-83.

26 Sels JPJE, Nauta JP, Menheere PPCA, Wolffenbuttel BHR, Nieuwenhuijzen Kruseman AC. Miglitol (Bay m 1099) has no extrapancreatic effects in healthy volunteers. Br $\mathcal{F}$ Clin Pharmacol 1996; (in press).

27 Hofmann CA, Colca JR. New oral thiazolidinedione antidiabetic agents act as insulin sensitizers. Diabetes Care 1992; 15: $1075-8$

28 Cantello BCC, Cawthorne MA, Cottam GP, et al. [[w-(Heterocyclylamino)-alkoxy]benzyl]-2,4thiazolidinediones as potent antihyperglycemic agents. F Med Chem 1994; 37: 3977-85.

29 Nolan JJ, Ludvik B, Beerdsen P, Joyce $M$, Olefsky J. Improvement in glucose tolerance and insulin resistance in obese subjects treated with troglitazone. $N$ Engl $f$ Med 1994; 331: 1188-93

30 Suter SL, Nolan JJ, Wallace P, Gumbiner B, Olefsky JM. Metabolic effects of new oral subjects. Diabetes Care 1992; 15: 193-203.
31 Valiquett T, Balagtas C, Whitcomb R. Troglitazone dose-response study in patients with NIDDM. Diabetes 1995; 44 (suppl1): 109A

32 Beck-Nielsen H. Effects of GR92132X, a thiazolidinedione, in non-insulin-dependent diabetic patients. Diabetologia 1994; 37 (suppl 1): A209.

33 Kuzuya T, Kosaka K, Akanuma Y, Shigeta Y, Kaneko T, Shimizu N, CS-045 Study Group. One-year clinical trial of a new oral hypoglycemic agent, CS-045, in NIDDM patients. Diabetologia 1994; 37 (suppl ): A63.

34 Ogihara T, Rakugi $H$, Ikegami $H$, Mikami $H$ Masuo K. Enhancement of insulin sensitivity by troglitazone lowers blood pressure in diabetic troglitazone lowers blood pressure in diabetic

5 Dandona P, Khurana U, Aljada A, AbdelRahman E, Love J. Troglitazone as an antioxidant. Diabetes 1995; 44 (suppl 1): 57A.

36 Ghazzi M, Balagtas C, Perez J, Whitcomb R. Treatment of NIDDM patients with troglitazone is not associated with increased cardiac mass or impaired cardiac function. Diabetes 1995; 44 (suppl 1): 157A.

37 Macdonald I, King $\mathrm{P}$, Kong M-F, et al. Infusion of the human amylin analogue, pramlintide (AC137), delays gastric emptying in men with IDDM. Diabetologia 1995; 38 (suppl 1): A32.

38 Kolterman OG, Gottlieb A, Moyses C, Colburn W. Reduction of postprandial hyperglycemia in subjects with IDDM by intravenous infusion of AC137, a human amylin analogue. Diabetes Care 1995; 18: 1179-82

39 Kolterman OG, Gottlieb AB, Organ KA Thompson RG. Reduction of postprandia hyperglycaemia in patients with type II diabete by the human amylin analogue pramlintide

40 Thompson RG, Gottlieb AB, Peterson J. The human amylin analogue pramlintide (AC137) reduces mean 24-hour glucose in type diabetes. Diabetologia 1995; 38 (suppl): A44.

41 Gutniak M, Orskov C, Holst J, Ahren B, Efendic $S$. Antidiabetogenic effect of glucagonlike peptide-1 (7-36)amide in normal subjects 1992; 326: 1316-22.

42 Dupre J, Behme MT, Hramiak IM, et al. Glucagon-like peptide I reduces postprandia glycemic excursions in IDDM. Diabetes 1995; 44: $626-30$

43 Stout RW. Insulin and atheroma - 20-yr perspective. Diabetes Care 1990; 31: 631 - 54 .

4 ADA Consensus Statement. The pharmacolog cal treatment of hyperglycemia in NIDDM. Diabetes Care 1995; 18: 1510-8. 